\title{
Spectroscopic and crystallographic characterization of a new cathinone derivative: 1-phenyl-2-(butylamino)hexan-1-one hydrochloride ( $N$-butylhexedrone)
}

\author{
Marcin Rojkiewicz ${ }^{1}$ [D $\cdot$ Piotr Kuś $^{1} \cdot$ Joachim Kusz $^{2} \cdot$ Maria Książek $^{2} \cdot$ Aleksander Sochanik $^{3}$
}

Received: 9 December 2019 / Accepted: 26 January 2020 / Published online: 11 February 2020

(c) The Author(s) 2020

\begin{abstract}
Purpose In this study, a new cathinone derivative, $N$-butylhexedrone, emerged on new psychoactive substances (NPS) market in Poland was described and characterized.

Methods The compound was analyzed by gas chromatography—mass spectrometry, X-ray crystallography and infrared, Raman, ultraviolet-visible and nuclear magnetic resonance spectroscopic approaches.

Results We confirmed the presence of the compound in the seized material and obtained detailed and comprehensive physicochemical characterization of $\mathrm{N}$-butylhexedrone-new cathinone derivative available on the NPS market.

Conclusions In this study, we presented chromatographic, spectroscopic and crystallographic characterization of a new cathinone derivative that emerged on the NPS market in 2019. The obtained analytical data should be useful for forensic and toxicological purposes in quick and reliable compound identification.
\end{abstract}

Keywords $N$-Butylhexedrone $\cdot$ New psychoactive substances $\cdot$ Mass spectrometry $\cdot$ X-ray crystallography $\cdot$ Infrared, Raman and ultraviolet-visible spectroscopies $\cdot$ NMR spectroscopy

\section{Introduction}

During the last decade, new psychoactive substances (NPS) have become a serious social and legal issue; their widespread availability translates into a serious threat to health and life of humans abusing them. Among compounds that dominate on the present NPS market are synthetic cathinones; their mode of action involves stimulation similar to that exerted by amphetamine or cocaine. There are numerous

Electronic supplementary material The online version of this article (https://doi.org/10.1007/s11419-020-00525-y) contains supplementary material, which is available to authorized users.

Marcin Rojkiewicz

marcin.rojkiewicz@us.edu.pl

1 Institute of Chemistry, University of Silesia, 9 Szkolna Street, 40-006 Katowice, Poland

2 Institute of Physics, University of Silesia, 175 Pułku Piechoty Street, 41-500 Chorzów, Poland

3 Center for Translational Research and Molecular Biology of Cancer, Maria Skłodowska-Curie Memorial Cancer Centre and Institute of Oncology, 44-100 Gliwice, Poland reports of cathinone derivatives' effects and overdosing case reports [1-6].

Synthetic cathinones are a widespread class of compounds present for years on the NPS market, but successive chemical modifications make them an analytical challenge for toxicologists, medics or law enforcement officers. In this report, we present physicochemical characteristics of $\mathrm{N}$-butylhexedrone hydrochloride (Fig. 1) - a novel derivative identified in the evidence material seized by police officers at the beginning of 2019 in Poland. The study results presented herein are a continuation of our previous reports concerning NPS and could be used for rapid and unequivocal identification of a given compound in crime investigation and toxicology laboratories [7, 8]. Of particular relevance are crystallographic studies, because knowledge of cell parameters for a compound allows for its fast noninvasive identification without the need for preliminary sample preparation. Because the material that has emerged on the NPS market and was seized contains very often crystal particles, generated crystallographic data may be further used for identification [9-11].

The data for characterizing the substances were obtained by gas chromatography—mass spectrometry (GC-MS), 


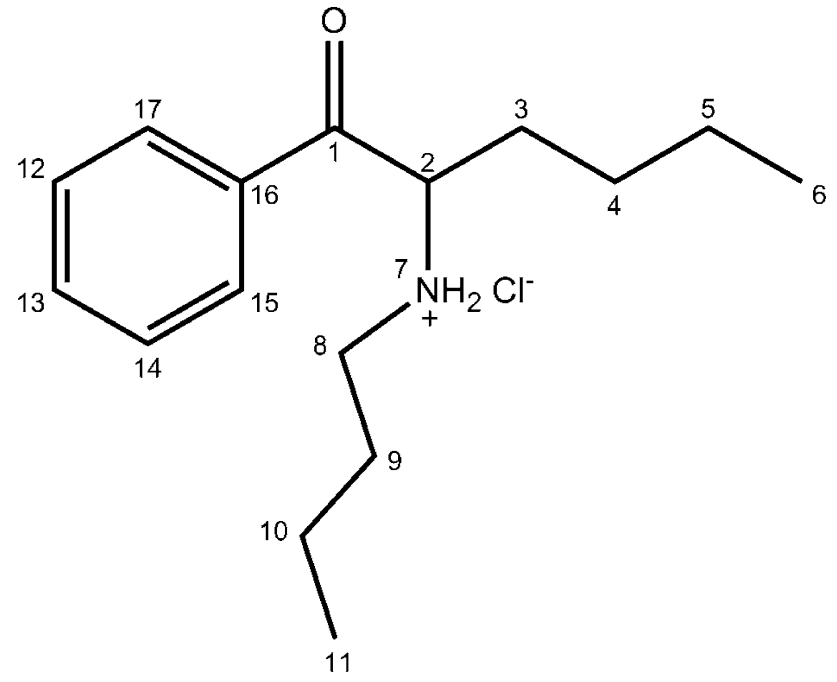

Fig. 1 Structure of 1-phenyl-2-(butylamino)hexan-1-one hydrochloride ( $N$-butylhexedrone)

direct infusion electrospray ionization mass spectrometry (ESI-MS), infrared (IR), Raman and ultraviolet-visible (UV-VIS) spectroscopies, X-ray crystallography and nuclear magnetic resonance (NMR) spectroscopy. To our knowledge, this is the first report that identifies in the seized material and characterizes $\mathrm{N}$-butylhexedrone in detail circulated on the NPS market. Some data for this compound are available in the report from Slovenian National Forensic Laboratory [12].

\section{Materials and methods}

\section{Chemicals}

In our study, all reagents used were of the HPLC or MS purity grade. Water (Chromasolv), methanol, isopropanol and deuterated chloroform $\left(\mathrm{CDCl}_{3}\right.$ for $\mathrm{NMR}$ analysis) were purchased from Sigma-Aldrich (Poznań, Poland).

\section{Sample preparation}

The sample was provided by drug enforcement agencies as material seized on the illicit drug market and was in pure powdered form. For the purpose of GC and ESI-MS, the 10-mg sample was dissolved in 1-mL methanol without the need for ultrasonication. An aliquot of $10 \mu \mathrm{L}$ was collected from the solution and diluted 100-fold with methanol and analyzed by GC-MS and ESI-MS. For NMR spectroscopic analysis, $10 \mathrm{mg}$ of the powdered sample was dissolved in $0.6 \mathrm{~mL} \mathrm{CDCl}_{3}$. For the IR, Raman and UV-VIS purpose, the 5-mg aliquot sample was taken for analysis. The IR and Raman analyses were performed without any further sample treatment, and for the UV-VIS analysis, the samples were dissolved and diluted in methanol.

\section{GC-MS analysis}

For GC-MS analysis, the Thermo Trace Ultra chromatograph was used, coupled with the Thermo DSQ mass spectrometer (Thermo Scientific, Waltham, MA, USA). The analyses were carried out with use of the $\mathrm{Rxi}^{\circledR}{ }^{\circledR}-5 \mathrm{Sil}$ MS column (Restek, Bellefonte, PA, USA). The following working parameters were employed: injector temperature, $260^{\circ} \mathrm{C}$; oven temperatures, $100{ }^{\circ} \mathrm{C}$ for $2 \mathrm{~min}$, ramp at $20^{\circ} \mathrm{C} / \mathrm{min}$ to $260^{\circ} \mathrm{C}$; the carrier gas (helium) flow rate, $1.2 \mathrm{~mL} \mathrm{~min}^{-1}$; MS transfer line temperature, $250{ }^{\circ} \mathrm{C}$; MS source temperature, $250{ }^{\circ} \mathrm{C}$; the injection volume, $1 \mu \mathrm{L}$, the splitless mode.

\section{Direct infusion electrospray ionization mass spectrometry}

Thermo TSQ Vantage mass spectrometer with electrospray ionization source (Thermo Scientific) was used. The following working parameters for the direct infusion ESI-MS experiment were employed: sheath gas pressure, 5 psi; heated (H)-ESI vaporizer temperature, $50{ }^{\circ} \mathrm{C}$; spray voltage, $3500 \mathrm{~V}$; ion transfer tube temperature, $50{ }^{\circ} \mathrm{C}$; direct infusion syringe flow rate, $5 \mu \mathrm{L} / \mathrm{min}$. The obtained data were processed using Xcalibur and TSQTune software (Thermo Scientific). The analytes were electrosprayed in the positive mode (ESI(+)-MS). Fragmentation in the ESI-MS ${ }^{2}$ mode was carried out in the scanning range of $m / z 50-255$. The ESI-carrier and collision gases were nitrogen and argon, respectively.

\section{NMR spectroscopy}

The NMR spectra of the samples were recorded with use of the UltraShield $400 \mathrm{MHz}$ apparatus (Bruker, Bremen, Germany), and $\mathrm{CDCl}_{3}$ was used as a solvent. The data were collected with the chemical shift referenced to a residual solvent signal.

\section{Fourier transform infrared (FT-IR), Raman and UV-VIS spectroscopies}

The IR spectrum of the powder evidence material was acquired with use of the Nicolet iS50 FT-IR spectrometer (Thermo Scientific), using the attenuated total reflection technique, and the spectrum was collected in the wave number range $3500-400 \mathrm{~cm}^{-1}$. Raman measurements were taken using a Thermo Scientific ${ }^{\mathrm{TM}}$ DXR ${ }^{\mathrm{TM}} 2 \mathrm{xi}$ Raman imaging microscope. The data were collected using a $780 \mathrm{~nm}$ laser. The UV-VIS absorption spectrum was recorded in the methanol solution using the Thermo Scientific Evolution 
160 UV-VIS spectrophotometer, and the spectrum was collected in range of wavelength 190-400 nm. The UV-VIS absorption spectrum was recorded in quartz cuvette with $1 \mathrm{~cm}$ light path length.

\section{X-ray spectroscopy}

The single-crystal X-ray experiments were performed at $100 \mathrm{~K}$. The data were collected using a SuperNova kappa diffractometer with Atlas charge coupled device detector (Agilent Technologies, Santa Clara, CA, USA). For the integration of the collected data, the CrysAlis ${ }^{\text {Pro }}$ software (version 1.171.38.41q, 2015; Rigaku Oxford Diffraction, Rigaku, Tokyo, Japan) was used. The structures were solved using direct methods with the SHELXS-2013 software, and the solutions were refined using SHELXL-2018/3 program [13]. CCDC 1963389 and CCDC 1963390 contain supplementary crystallographic data for this paper. These data can be obtained free of charge from the Cambridge Crystallographic Data Centre via: www.ccdc.cam.ac.uk/data_reque st/cif.

\section{Results}

\section{GC-MS and ESI-MS}

The sample was analyzed by GC-MS, and the resulting mass spectrum of the compound is shown in Fig. 2.
In the mass spectrum obtained in the EI-MS mode, one main fragment ion was detected at $\mathrm{m} / \mathrm{z}$ 142. Other less intense fragments present in the spectrum were $\mathrm{m} / \mathrm{z} 77$, 86 and 105. Possible structures of the fragmentation products derived from the parent structure of the investigated compound are presented in Fig. 3, which is in accordance with fragmentation pathways proposed in the literature [14]. The obtained spectrum is also identical with that originating from the report of Slovenian National Forensic Laboratory [12]. When compared with the mass spectrum of NEH ( $N$-ethylhexedrone) [8], it can be noticed that there are the same peaks present at $\mathrm{m} / \mathrm{z} 77$ and 105 , and the spectrum differs only in the base peak found at $\mathrm{m} / \mathrm{z} 114$ for NEH. The difference of 28 Da between $\mathrm{m} / \mathrm{z} 114(\mathrm{NEH})$ and $m / z 142$ ( $N$-butylhexedrone) corresponds well with the presence of two additional methylene groups in the investigated compound. This suggest the bond cleavage between carbon 1 and 2 (carbon numbering shown in Fig. 1) while the fragmentation. Also, it can be noticed that the difference of 28 Da can be observed in peaks found at $\mathrm{m} / z 58$ for $\mathrm{NEH}$ and at $\mathrm{m} / \mathrm{z} 86$ for $\mathrm{N}$-butylhexedrone.

In the ESI-MS spectrum, the protonated molecule $\left[\mathrm{M}+\mathrm{H}^{+}\right]$was seen at $m / z 248$ (Fig. S1). The sample was directly infused to the ion source. The sample was also analyzed in the MS/MS mode (Fig. S2). In the MS/ MS mode, elimination of water molecule was observed $\left[\mathrm{M}+\mathrm{H}^{+}-\mathrm{H}_{2} \mathrm{O}\right]$, which is characteristic for certain cathinone derivatives $[15,16]$. Compound optimization for selected reaction monitoring experiments was also performed. Three most abundant peaks were found at $m / z 91$, 118 and 174. The probable fragmentation pathways are presented in Fig. 4.
Fig. 2 Gas chromatography-electron ionization-mass spectrum of compound $\mathbf{1}$

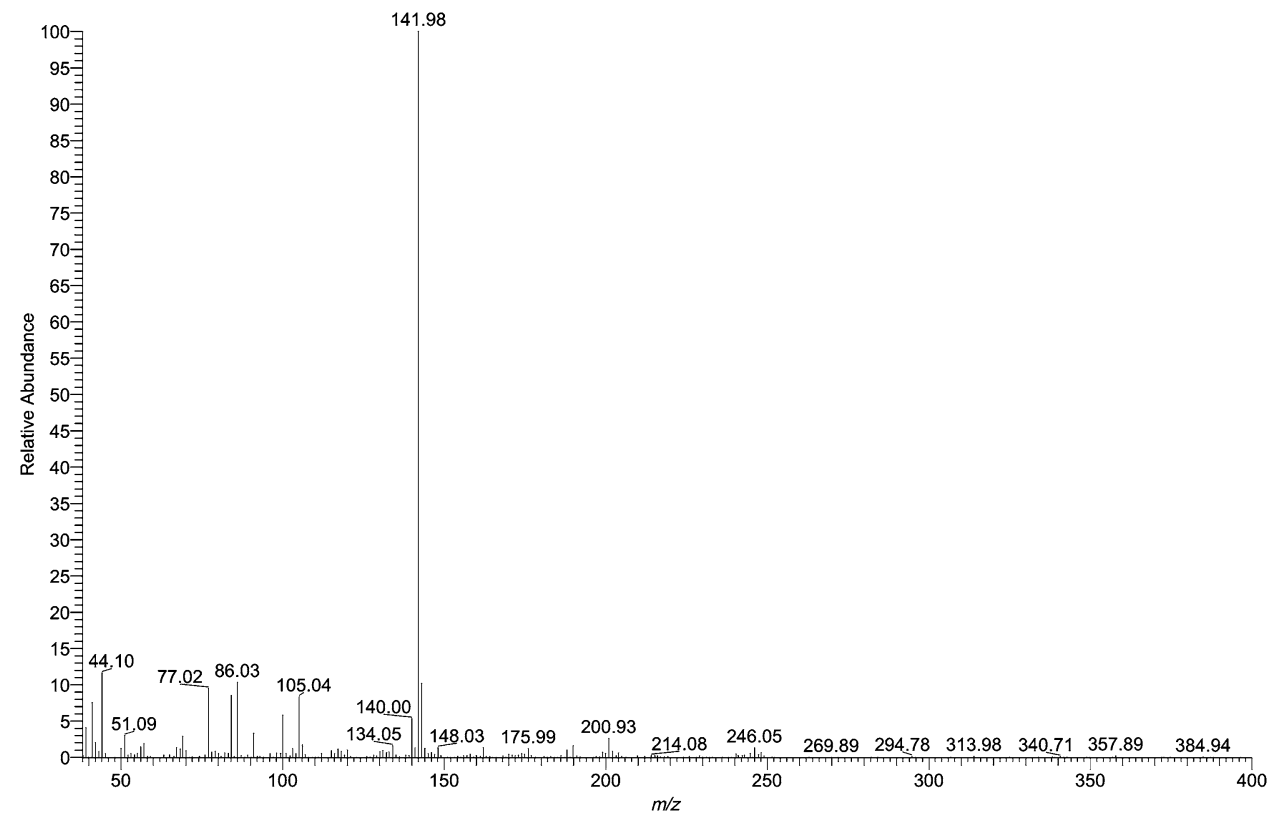


Fig. 3 Electron ionization-mass spectrometry fragmentation pathways of compound $\mathbf{1}$

Fig. 4 Electrospray ionizationmass spectrometry fragmentation pathways of compound $\mathbf{1}$
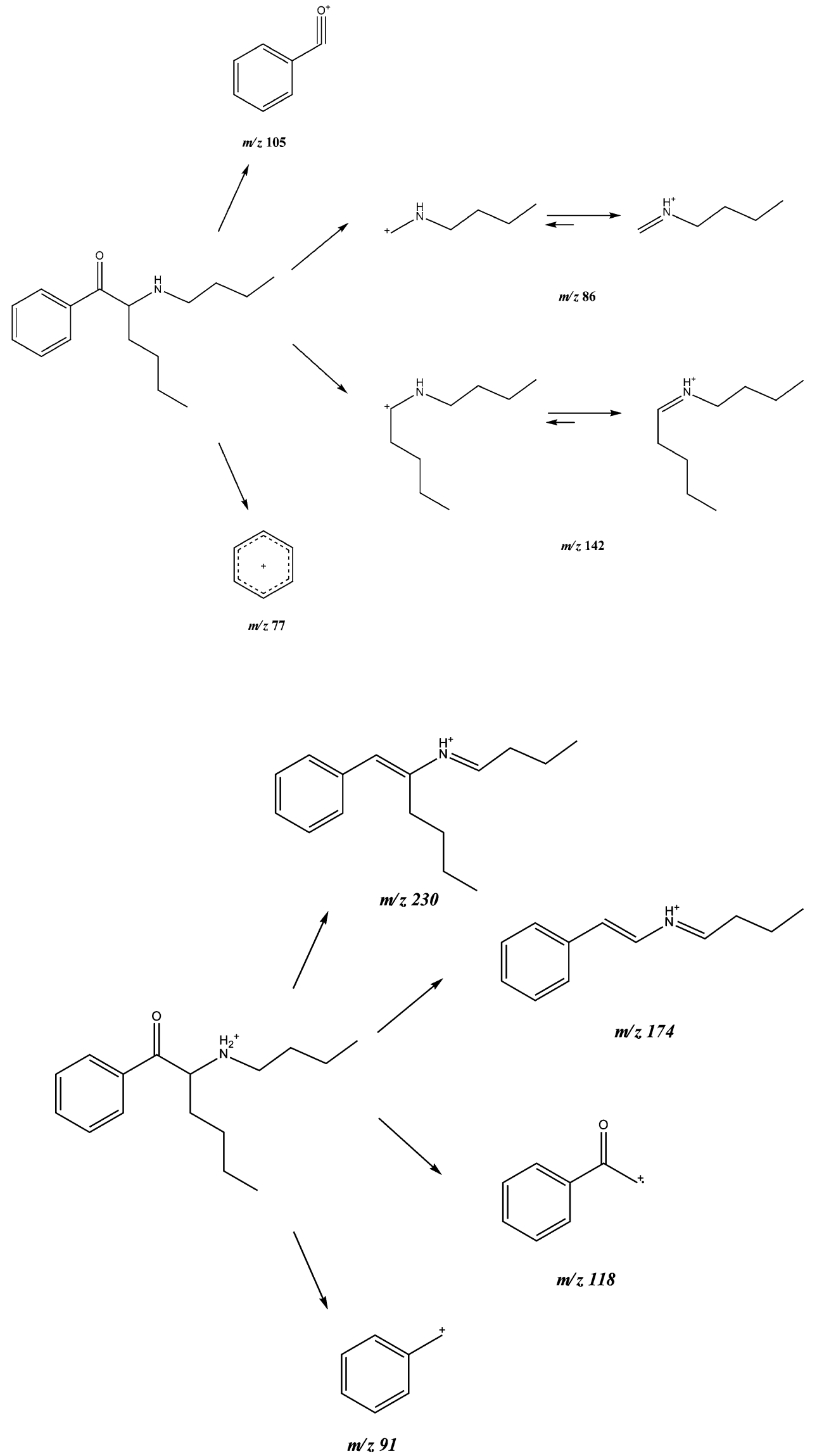


\section{${ }^{1} \mathrm{H}$ and ${ }^{13} \mathrm{C}$ NMR spectroscopy}

The NMR spectroscopy was employed to confirm the structure of the investigated compound (Figs. S3 and S4). The data for $\mathrm{N}$-butylhexedrone are presented in Table 1 (atom numbering according to Fig. 1).

\section{IR, Raman, UV-VIS spectra and melting point}

IR and Raman techniques can be useful for characterizing NPS, especially during quick identification and profiling (fingerprinting). In the IR spectrum (Fig. S5), a strong carbonyl stretch at $1687 \mathrm{~cm}^{-1}$ was observed. Aliphatic and aromatic C-H stretching at $2700-3000 \mathrm{~cm}^{-1}$ can be observed as well. In the Raman spectroscopy (Fig. S6), strong $\mathrm{C}=\mathrm{O}$ band was seen at $1691 \mathrm{~cm}^{-1}$. The $\mathrm{C}-\mathrm{C}$ aromatic bands lay actually at the same wave number values as in the IR spectrum. The UV spectra recorded by UV-VIS spectrometry showed absorption maxima at 202 and $251 \mathrm{~nm}$ for the investigated compound (Fig. S7). Melting point of the $N$-butylhexedrone hydrochloride measured in the classical way was $138-140{ }^{\circ} \mathrm{C}$.

\section{X-ray studies}

Compound 1 formed orthorhombic crystals in the $P 2{ }_{1}{ }_{1} 2_{1}$ space group (form A) or monoclinic crystals in the $P 2{ }_{l} / c$ space group (form B) when crystallized from dimethyl sulfoxide or ethyl alcohol, respectively. In the orthorhombic crystals, all molecules occur as the $R$-isomers. In the monoclinic crystals, both enantiomers occur together with additional ethyl alcohol and water molecules in the unit cell. Crystal data and structure refinement for both crystals are summarized in Table 2. The molecular structures and packing diagrams are shown in Figs. 5, 6, 7, 8. All distances and angles in the molecular structures of both crystals were typical. The distances between $\mathrm{NH}_{2}$ groups and two chlorine ions in form $\mathrm{A}$ and two chlorine ions in form $\mathrm{B}$ lay within 2.267-2.393 $\AA$ (at $\Theta$ angles: $152.90-169.99^{\circ}$ ) and within 2.243-2.406 $\AA$ (at $\Theta$ angles: $150.50-169.55^{\circ}$ ), respectively. These values are very similar to the data reported for other cathinone derivatives [8]. Torsion angle $\mathrm{C} 7 \mathrm{C} 12 \mathrm{~N} 1 \mathrm{C} 13$ was $73.70^{\circ}$ in $R$-isomer of form A. Torsion angles $\mathrm{C} 7 \mathrm{C} 12 \mathrm{~N} 1 \mathrm{C} 13$ were identical in both enantiomers $\left( \pm 71.10^{\circ}\right)$ in crystals of form B. In crystals of form A, no weak hydrogen bonds were present between cathinone molecules. In crystals of form B, two molecules: $R$-and $S$-isomers, can form pairs in which the $\pi \cdots \pi$ interactions between phenyl rings may occur, which is shown in Fig. S8. The phenyl rings are separated from each other by $3.363 \AA$ and centroid distance of $4.076 \AA$ (124.23 ${ }^{\circ}$ angle).

Other short distances occurring in the structure of compound 1: two $\mathrm{C}-\mathrm{H} \cdots \mathrm{Cl}$ and two $\mathrm{N}-\mathrm{H} \cdots \mathrm{Cl}$ short distances, testifying to the presence of weak interactions between molecules in form A are shown in Fig. S9. Calculated $\mathrm{C}-\mathrm{H} 12 \cdots \mathrm{Cl} 1$ distance $\left(2.572 \AA ; 171.1^{\circ}\right)$ and $\mathrm{C}-\mathrm{H} 6 \cdots \mathrm{Cl} 1$ distance $\left(2.80 \AA \tilde{\AA} ; 169.3^{\circ}\right)$ are shorter than sum of van der Waals radii $=2.95 \AA$.

\section{Discussion}

Crystallographic methods allow to define precisely the particular components of a sample provided it contains monocrystalline components amenable to mechanical
Table $1{ }^{1} \mathrm{H}$ and ${ }^{13} \mathrm{C}$ nuclear magnetic resonance data for compound 1

\begin{tabular}{lll}
\hline Atom position & $\begin{array}{l}\text { Carbon chemi- } \\
\text { cal shifts }(\mathrm{ppm})\end{array}$ & Proton chemical shifts $(\mathrm{ppm})$ \\
\hline 1 & 195.60 & - \\
2 & 61.64 & $5.14(\mathrm{~s}, 1 \mathrm{H})$ \\
3 & 30.34 & $2.21-2.28(\mathrm{~m}, 1 \mathrm{H}) ; 2.31-2.39(\mathrm{~m}, 1 \mathrm{H})$ \\
4 & 22.36 & $1.98-2.02(\mathrm{~m}, 2 \mathrm{H})$ \\
5 & 19.98 & $1.26-1.32(\mathrm{~m}, 3 \mathrm{H}) ; 1.34-1.44(\mathrm{~m}, 3 \mathrm{H})($ signal from protons nos. $5,9,10)$ \\
6 & 13.39 & $0.81(\mathrm{t}, J=6.8 \mathrm{~Hz}, 3 \mathrm{H})$ \\
7 & - & $8.42(\mathrm{bs}, 1 \mathrm{H}) ; 10.83(\mathrm{bs}, 1 \mathrm{H})$ \\
8 & 47.07 & $2.92(\mathrm{bs}, 1 \mathrm{H}) ; 3.23(\mathrm{bs}, 1 \mathrm{H})$ \\
9 & 26.75 & $1.26-1.32(\mathrm{~m}, 3 \mathrm{H}) ; 1.34-1.44(\mathrm{~m}, 3 \mathrm{H})($ signal from protons nos. 5, 9, 10) \\
10 & 22.36 & $1.26-1.32(\mathrm{~m}, 3 \mathrm{H}) ; 1.34-1.44(\mathrm{~m}, 3 \mathrm{H})($ signal from protons nos. $5,9,10)$ \\
11 & 13.46 & $0.93(\mathrm{t}, J=7.3 \mathrm{~Hz}, 3 \mathrm{H})$ \\
12,14 & 128.85 & $7.56(\mathrm{t}, J=7.6 \mathrm{~Hz}, 2 \mathrm{H})$ \\
13 & 134.39 & $7.70(\mathrm{t}, J=7.3 \mathrm{~Hz}, 1 \mathrm{H})$ \\
15,17 & 129.12 & $8.02-8.04(\mathrm{~d}, 2 \mathrm{H})$ \\
16 & 134.64 & -
\end{tabular}

The numbering of carbon atoms is given in Fig. 1 
Table 2 Crystal data and structure refinement for compound 1

\begin{tabular}{|c|c|c|}
\hline Chemical formula & $\begin{array}{l}\mathrm{C}_{16} \mathrm{H}_{26} \mathrm{NOCl} \\
\text { (form A) }\end{array}$ & $\begin{array}{l}\mathrm{C}_{16} \mathrm{H}_{26} \mathrm{NOCl} \cdot 0.58 \\
2\left(\mathrm{C}_{2} \mathrm{H}_{5} \mathrm{OH}\right) \cdot 0.418( \\
\left.\mathrm{H}_{2} \mathrm{O}\right) \\
(\text { form B) }\end{array}$ \\
\hline Molecular weight & 283.83 & 318.15 \\
\hline Temperature (K) & 100 & 100 \\
\hline Crystal system & Orthorhombic & Monoclinic \\
\hline Space group & $P 2_{1} 2_{1} 2_{1}$ & $P 2_{l} / c$ \\
\hline$a(\AA)$ & $7.4206(5)$ & $11.7469(2)$ \\
\hline$b(\AA)$ & $11.4863(9)$ & $7.4117(1)$ \\
\hline$c(\AA)$ & $19.6959(12)$ & $21.6645(3)$ \\
\hline$\beta\left({ }^{\circ}\right)$ & 90 & $100.684(2)$ \\
\hline$V\left(\AA^{3}\right)$ & $1678.8(2)$ & $1853.51(5)$ \\
\hline$D_{x}\left(\mathrm{~g} \mathrm{~cm}^{-3}\right)$ & 1.123 & 1.140 \\
\hline$Z$ & 4 & 4 \\
\hline Absorption coefficient $\left(\mathrm{mm}^{-1}\right)$ & 1.95 & 1.852 \\
\hline$F(000)$ & 616 & 693 \\
\hline Crystal size (mm) & $0.50 \times 0.07 \times 0.02$ & $0.37 \times 0.03 \times 0.02$ \\
\hline \multicolumn{3}{|l|}{ Data collection and structure solution: } \\
\hline Data collected & 9242 & 12,617 \\
\hline Independent reflections & 3237 & 3685 \\
\hline Observed reflections $[I>2 \sigma(I)]$ & 2780 & 3555 \\
\hline$R$ (int.) & 0.047 & 0.019 \\
\hline Completeness (\%) & 98 & 100 \\
\hline$T_{\max } / T_{\min }$ & $1.000 / 0.445$ & $1.000 / 0.741$ \\
\hline No. of parameters & 175 & 202 \\
\hline$R 1[I>2 \sigma(I)]$ & 0.087 & 0.057 \\
\hline$w R 2$ (all data) & 0.242 & 0.167 \\
\hline $\mathrm{S}$ & 1.12 & 1.07 \\
\hline Largest diff. peak and hole $\left[\mathrm{e} \AA^{-3}\right]$ & $1.14,-0.63$ & $1.03,-1.06$ \\
\hline CCDC & $1,963,390$ & $1,963,389$ \\
\hline
\end{tabular}

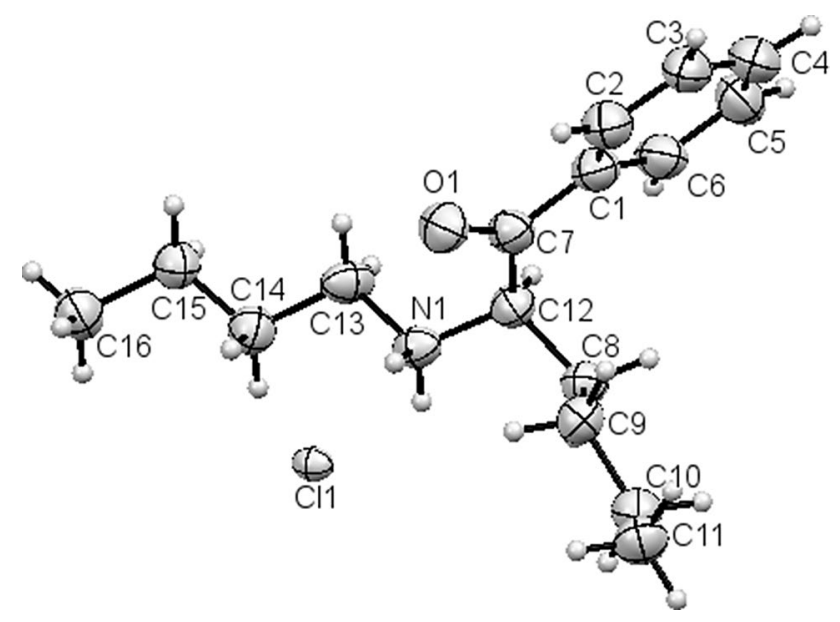

Fig. 5 (R)-Enantiomer molecule of compound 1 (form A) in the crystal. Ellipsoids correspond to $50 \%$ probability levels separation. When the sample presents a mixture and its components have to be separated by chromatographic methods or the sample is an amorphous substance requiring recrystallization in order to obtain monocrystals, there is a concern of incorporating solvent molecules in crystals of a given compound. This situation has occurred in the particular case presented herein. Recrystallization led to the incorporation of solvent molecules (water and ethanol) in the elementary cell during formation of crystals. Our previously performed analyses of directly marketed NPS samples never revealed crystals of cathinone hydrochloride (in one case disulphuric (VI) acid [17]) salts that would also contain solvents in elementary cells. Such cases need to be considered when analyzing unknown samples by crystallographic methods.

It should also be mentioned that very recently during preparation of this manuscript a report has appeared [18] dealing with physical and chemical characterization of $N$-butylhexedrone. These Russian investigators analyzed compound 1 using chromatographic methods coupled with mass spectrometry, and NMR and IR spectroscopies. Their 
Fig. 6 Packing diagram for compound 1 (form A): view along $a$-axis
Fig. 7 Two $(S)$-enantiomer molecules of compound $\mathbf{1}$ (form B) with ethanol (a) or water (b) in the crystal. Ellipsoids correspond to $50 \%$ probability levels

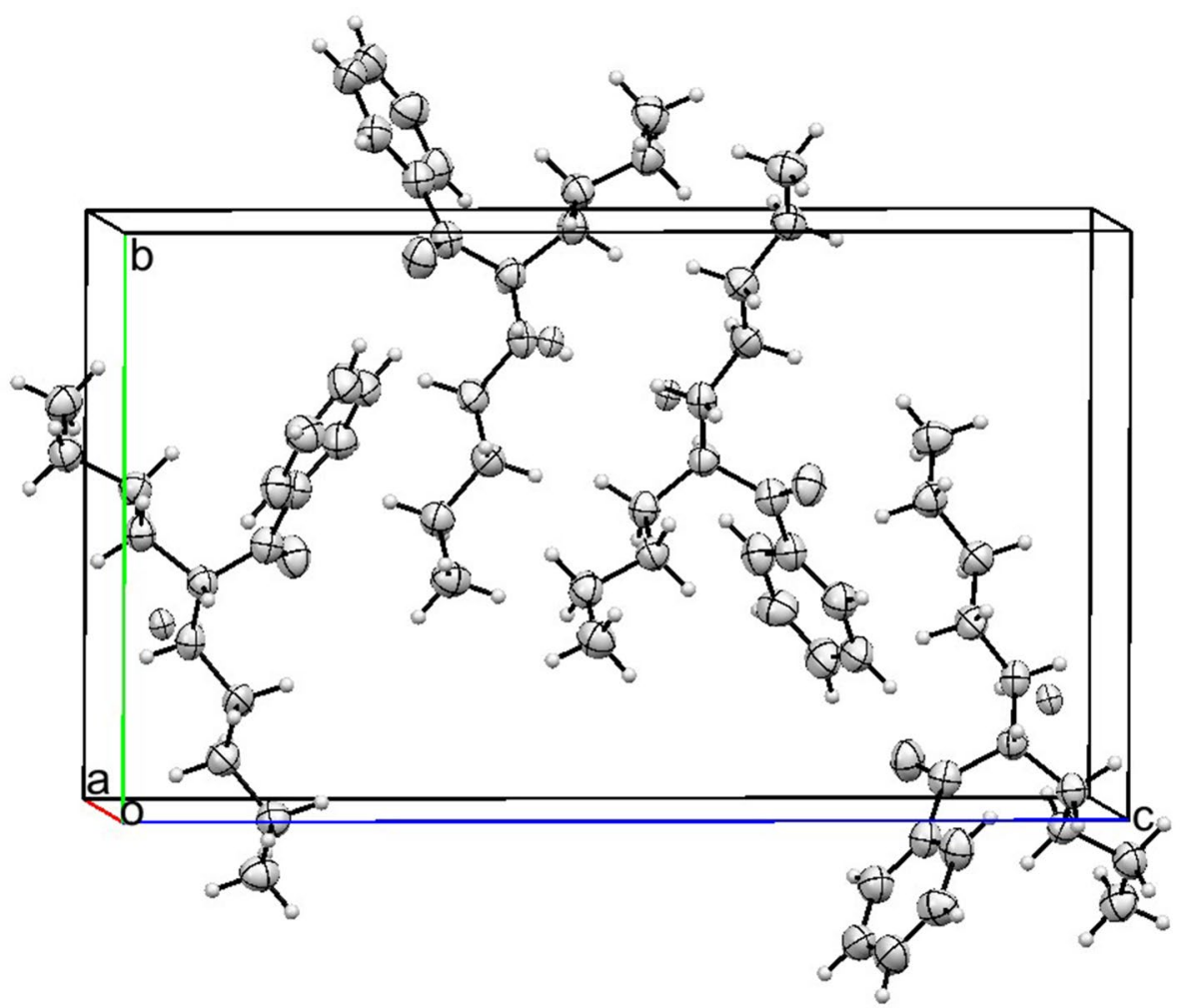

$\mathbf{a}$

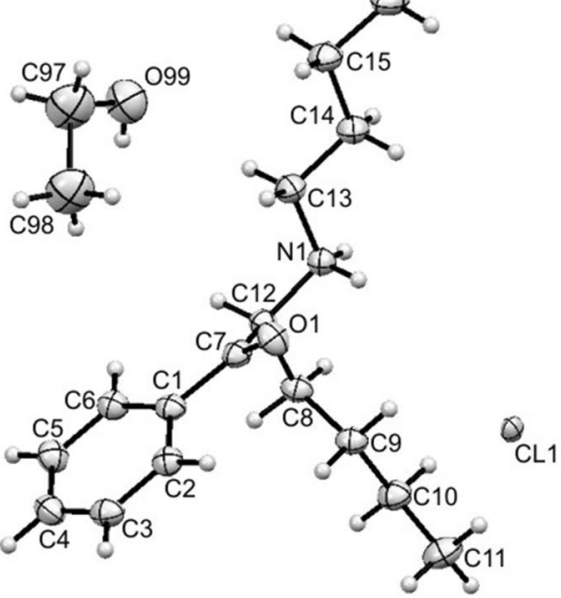

b

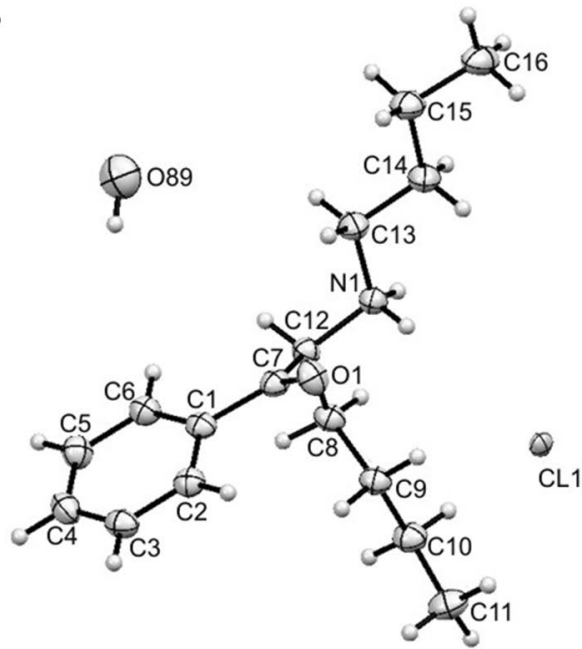

reported results correlate well with data presented herein. However, in our study we performed ultraviolet-visible spectroscopy and crystallographic analyses which add, in our opinion, some interesting data from the perspective of full characteristics of NPS and which, by far, are underestimated in forensic science. For many unknown compounds which surface on the NPS market, it is feasible to obtain monocrystals from analyzed samples. They would be suitable for crystallographic analyses allowing unequivocal substance identification. In our opinion, co-implementation of crystallographic methods in NPS analyses ought to meet with wider attention from toxicologists and forensic scientists.

\section{Conclusions}

In this study, we presented chromatographic, spectroscopic and crystallographic characterization of a new cathinone derivative that emerged on the NPS market in 2019. The obtained analytical data should be useful for forensic and toxicological purposes in quick and reliable compound 
Fig. 8 Packing diagram for compound 1 (form B) with ethanol molecules: view along $b$-axis. Water molecules and one ethanol position were omitted for clarity

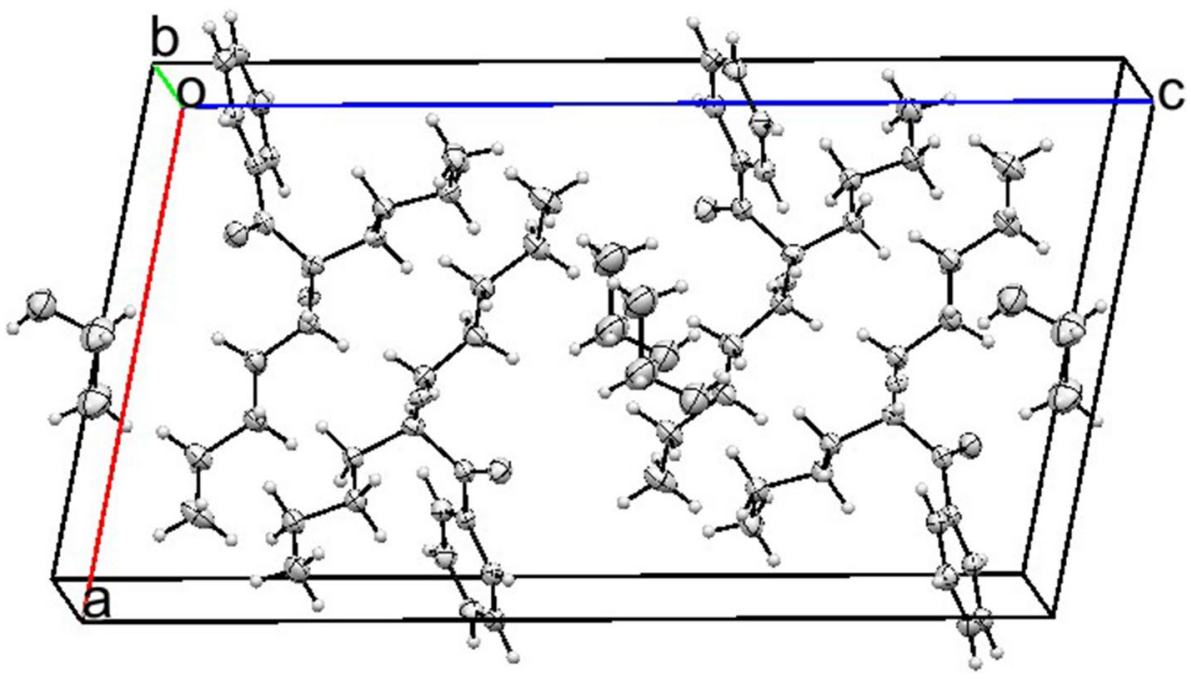

identification. Our report is linked to CCDC repository entry for this compound, and its characteristics can be found there including elementary cell data, of particular usefulness for quick analysis. Although some data for the investigated compound have been available $[12,18]$, to our knowledge this study provides the first detailed and comprehensive report including X-ray crystallographic data on $N$-butylhexedrone.

Acknowledgements We wish to thank Dr. Barbara Hachuła for IR and Raman spectra measurements.

\section{Compliance with ethical standards}

Conflict of interest The authors declare that they have no conflict of interest.

Ethics approval This article does not contain any studies with human participants or animals performed by any of the authors.

Open Access This article is licensed under a Creative Commons Attribution 4.0 International License, which permits use, sharing, adaptation, distribution and reproduction in any medium or format, as long as you give appropriate credit to the original author(s) and the source, provide a link to the Creative Commons licence, and indicate if changes were made. The images or other third party material in this article are included in the article's Creative Commons licence, unless indicated otherwise in a credit line to the material. If material is not included in the article's Creative Commons licence and your intended use is not permitted by statutory regulation or exceeds the permitted use, you will need to obtain permission directly from the copyright holder. To view a copy of this licence, visit http://creativecommons.org/licenses/by/4.0/.

\section{References}

1. Adamowicz P, Geroń J, Gil D, Lechowicz W, Skulska A, Tokarczyk B (2016) The prevalence of new psychoactive substances in biological material-a three-year review of casework in Poland. Drug Test Anal 8:63-70. https://doi.org/10.1002/dta.1924
2. Zawilska J, Wojcieszak J (2017) $\alpha$-Pyrrolidinophenones: a new wave of designer cathinones. Forensic Toxicol 35:201-216. https ://doi.org/10.1007/s11419-016-0353-6

3. Couto RAS, Gonçalves LM, Carvalho F, Rodrigues JA, Rodrigues CMP, Quinaz MB (2018) The analytical challenge in the determination of cathinones, key-players in the worldwide phenomenon of novel psychoactive substances. Crit Rev Anal Chem 48:372-390. https://doi.org/10.1080/10408347.2018.1439724

4. Zawilska JB, Wojcieszak J (2013) Designer cathinones-an emerging class of novel recreational drugs. Forensic Sci Int 231:42-53. https://doi.org/10.1016/j.forsciint.2013.04.015

5. Romanek K, Stenzel J, Schmoll S, Schrettl V, Geith S, Eyer F, Rabe C (2017) Synthetic cathinones in Southern Germanycharacteristics of users, substance-patterns, co-ingestions, and complications. Clin Toxicol 55:573-578. https://doi. org/10.1080/15563650.2017.1301463

6. Glicksberg L, Winecker R, Miller C, Kerrigan S (2018) Postmortem distribution and redistribution of synthetic cathinones. Forensic Toxicol 36:291-303. https://doi.org/10.1007/s1141 9-018-0403-3

7. Rojkiewicz M, Kuś P, Kusz J, Książek M (2018) Spectroscopic and crystallographic characterization of two cathinone derivatives: 1-(4-fluorophenyl)-2-(methylamino)pentan-1-one (4-FPD) hydrochloride and 1-(4-methylphenyl)-2-(ethylamino)pentan1-one (4-MEAP) hydrochloride. Forensic Toxicol 36:141-150. https://doi.org/10.1007/s11419-017-0393-6 (open access article)

8. Kuś P, Rojkiewicz M, Kusz J, Książek M, Sochanik A (2019) Spectroscopic characterization and crystal structures of four hydrochloride cathinones: $N$-ethyl-2-amino-1-phenylhexan1-one (hexen, $\mathrm{NEH}), \mathrm{N}$-methyl-2-amino-1-(4-methylphenyl)3-methoxypropan-1-one (mexedrone), N-ethyl-2-amino1-(3,4-methylenedioxyphenyl)pentan-1-one (ephylone) and $\mathrm{N}$-butyl-2-amino-1-(4-chlorophenyl)propan-1-one (4-chlorobutylcathinone). Forensic Toxicol 37:456-464. https://doi. org/10.1007/s11419-019-00477-y (open access article)

9. Nycz JE, Małecki G, Zawiązalec M, Paździorek T (2011) $\mathrm{X}$-ray structures and computational studies of several cathinones. J Mol Struct 1002:10-18. https://doi.org/10.1016/j.molst ruc.2011.06.030

10. Trzybiński D, Niedziałkowski P, Ossowski T, Trynda A, Sikorski A (2013) Single-crystal X-ray diffraction analysis of designer drugs: hydrochlorides of metaphedrone 
and pentedrone. Forensic Sci Int 232:e28-e32. https://doi. org/10.1016/j.forsciint.2013.07.012

11. Siczek M, Siczek M, Szpot P, Zawadzki M, Wachełko O (2019) Crystal structures and spectroscopic characterization of four synthetic cathinones: 1-(4-chlorophenyl)-2-(dimethylamino)propan1-one (N-methyl-clephedrone, 4-CDC), 1-(1,3-benzodioxol-5-yl)2-(tert-butylamino)propan-1-one (tBuONE, tertylone, MDPT), 1-(4-fluorophenyl)-2-(pyrrolidin-1-yl)hexan-1-one (4F-PHP) and 2-(ethylamino)-1-(3-methylphenyl)propan-1-one (3-methylethylcathinone, 3-MEC). Crystals 9:555. https://doi.org/10.3390/ cryst9110555 (open access article)

12. National Forensic Laboratory, Slovenia (2019) Analytical report: butylhexedrone. https://www.policija.si/apps/nfl_response_ web/0_Analytical_Reports_final/Butylhexedrone-ID-2065-19_ report.pdf. Accessed 12 Nov 2019

13. Sheldrick GM (2015) Crystal structure refinement with SHELXL Acta Cryst C71:3-8. https://doi.org/10.1107/S2053229614024218 (open access article)

14. Matsuta S, Katagi M, Nishioka H, Kamata H, Sasaki K, Shima N, Kamata T, Miki A, Tatsuno M, Zaitsu K, Tsuboi K, Tsuchihashi H, Suzuki K (2014) Structural characterization of cathinone-type designer drugs by EI mass spectrometry. Jpn J Forensic Sci Technol 19:77-89. https://doi.org/10.3408/jafst.19.77 (open access article, in Japanese with English abstract)
15. Fornal E (2014) Study of collision-induced dissociation of electrospray-generated protonated cathinones. Drug Test Anal 6:705-715. https://doi.org/10.1002/dta.1573

16. Fornal E (2013) Formation of odd-electron product ions in collision-induced fragmentation of electrospray-generated protonated cathinone derivatives: aryl $\alpha$-primary amino ketones. Rapid Commun Mass Spectrom 27:1858-1866. https://doi.org/10.1002/ rem.6635

17. Kuś P, Kusz J, Książek M, Pieprzyca E, Rojkiewicz M (2018) Spectroscopic characterization and crystal structures of two cathinone derivatives: 1-(4-chlorophenyl)-2-(1-pyrrolidinyl) pentan-1-one (4-chloro- $\alpha$-PVP) sulfate and 1-(4methylphenyl)2-(dimethylamino)propan-1-one (4-MDMC) hydrochloride salts, seized on illicit drug market. Forensic Toxicol 36:178-184. https ://doi.org/10.1007/s11419-017-0381-x (open access article)

18. Shevyrin V, Eltsov O, Shafran Y (2020) Identification and analytical characterization of the synthetic cathinone $N$-butylhexedrone. Drug Test Anal 12:159-163. https://doi.org/10.1002/dta.2712

Publisher's Note Springer Nature remains neutral with regard to jurisdictional claims in published maps and institutional affiliations. 